\title{
DROGAS E NUTRIÇÃO: INTERAÇÕES E INCOMPATIBILIDADES
}

Hisako Shima*

SHIMA, H. Drogas e nutrição: interações e incompatibilidades. Rev. Esc. Enf. USP, São Paulo, 16(3) :255-264, 1982.

A absorção de drogas pode, às vezes, ser consideravelmente alterada conforme as condiçōes em que são ingeridas, ou seja, em jejum ou junto com alimentos ou fluidos. Além disso, alguns componentes alimentares não devem ser ingeridos com certas drogas por apresentarem efeitos adversos. O presente trabalho aborda essas interações $e$ incompatibilidades existentes entre as drogas e os alimentos.

\section{INTRODUÇÃO}

A interação entre duas ou mais drogas distintas tem sido bastante pesquisada e o assunto é abordado invariavelmente em todos os livros de farmacologia, o que não ocorre com a interação droga-alimento. Segundo HATHCOCK (1976), existe uma interrelação ampla e complexa entre ambos.

Uma droga administrada oralmente deve ser absorvida no trato gastro-intestinal em quantidade e velocidade que resulta em nivel circulante suficiente para exercer uma resposta de magnitude e duração desejadas (WELLING, 1977).

É sabido que vários fatores influem nesse processo de absorção: alguns são inerentes à própria droga - solubilidade, coeficiente de partição óleo/água, tamanho da molécula, grau de ionização e forma farmacêutica; outros são decorrentes do meio gastrintestinal - $\mathrm{pH}$, presença de alimentos e fluidos e, finalmente, os fatores próprios da mucosa intestinal por ocasião da administração da droga (GIESBRECHT \& ZYNGIER, 1979).

A interação droga-alimento, dependendo do seu tipo e grau, pode resultar em diminuição do nível e velocidade de absorção, afetando o efeito da droga no organismo receptor, ou em aumento da absorção a ponto de causar toxicidade.

- Professor Assistente do Departamento de Enfermagem Médico-Cirúrgica da Escola de Enfermagem da USP - disciplinas Nutriçăo e Dietética Aplicadas à Enfermagem I, II e III. Mestre em Ciência dos Alimentos. Nutricionista. 
Os estudos sobre a biodisponibilidade de drogas, entretanto, são em geral realizados com indivíduos em jejum, pois a maioria dos órgãos fiscalizadores assim o exigem; dessa forma, a aplicabilidade desses dados é questionável numa situação em que a droga é ingerida com os alimentos (TOOTHAKER \& WELLING, 1980).

$E$ evidente, portanto, a importância de maior conhecimento a respeito dessa interação para melhor controlar a relação entre a administração da droga e ingestão concomitante de alimentos e fluidos.

\section{INTERAÇÃO ALIMENTO - DROGA}

\section{Efeito indireto dos alimentos}

A presença do alimento desencadeia no trato gastrintestinal alterações fisiológicas como mudança do $\mathrm{pH}$, retardo da evacuação do conteúdo gástrico e menor velocidade de passagem intestinal. Assim, quando uma droga é ingerida concomitantemente com alimentos ou nas refeições, a sua absorção pode sofrer a interferência dessas alterações.

De modo geral, observa-se diminuição na velocidade de absorção sem que a quantidade absorvida seja afetada. Isso tem sido registrado nos casos de digoxina (GREENBLATT et alii, 1974; JOHNSON et alii, 1978), alclofenaque (SENNELLO et alii, 1978), diazepan (GREENBLATT et alii, 1978) e muitas outras drogas (WELLING, 1977).

No entanto, dependendo das caracteristicas da droga, essa passagem gastrintestinal retardada pode resultar em aumento ou diminuição do nível de absorção.

No caso da nitrofurantoína (BATES et alii, 1974; RESENBERG \& BATES, 1976) e espironolactona (MELANDER et alii, 1977) observou-se aumento da quantidade absorvida como resultado da melhor dissolução da droga ao permanecer por mais tempo no estômago.

Registrou-se ainda um aumento no nivel de absorção de riboflavina (LEVY \& JUSKO, 1966) e riboflavina-5'-fosfato (JUSKO \& LEVY, 1967) quando ingeridas com alimentos. Essas substâncias são absorvidas por mecanismo específico que é saturável; assim, quando ingeridas em jejum, passam rapidamente ao intestino saturando os sítios de absorção, o que não ocorre quando diluídas e retardadas pelos alimentos, resultando em maior eficiência de absorção.

Por outro lado, drogas sensíveis ao $\mathrm{pH}$ ácido podem sofrer degradação catalizada pelo ácido gástrico durante a sua permanência mais prolongada no estômago junto com os alimentos. A menor absorção do estearato de eritromicina, quando ingerido imediatamente após diferentes refeições (WELLING et alii, 1978), foi atribuída pelos autores a esse mecanismo, uma vez que se trata de um composto lábil a ácidos. 
A ingestão de alimentos pode, ainda em maior ou menor grau, dependendo do tipo e quantidade, alterar o $\mathrm{pH}$ gástrico e, conseqüentemente, a absorção da droga, pois, a maioria delas é absorvida através da mucosa intestinal em sua forma não ionizada (KOCH-WESER, 1974) ; assim, drogas de caráter fracamente ácido são mais bem absorvidas no pH ácido do estômago e as fracamente básicas, no meio alcalino do intestino; portanto, aspirina e barbitúricos, de caráter fracamente ácido, se tornam mais ionizados e menos absorvidos à medida que o $\mathrm{pH}$ do meio aumenta, ou seja, quando o pH estomacal é tamponado com a presença de alimentos.

\section{Efeito direto dos alimentos}

$\mathrm{O}$ alimento pode interagir diretamente com a droga por meio de diferentes mecanismos, afetando a sua absorção e biodisponibilidade.

1. Interação física. O próprio alimento atua como barreira física prevenindo o acesso da droga à superfície da mucosa do trato gastrintestinal. Esse mecanismo afeta, portanto, em maior ou menor grau, qualquer droga ingerida com alimentos ou nas refeições.

2. Complexação. A interferência de íons di e trivalentes $-\mathbf{F e}^{++}$, $\mathrm{Ca}^{++}$e $\mathrm{Mg}^{+++}$- na absorção de diferentes formas de tetraciclina é um fato bastante conhecido; esses ions complexam-se com o antibiótico reduzindo a sua eficiência de absorção, ocasionando a excreção fecal tanto dos minerais como da droga (KOCH-WESER, 1974; LAMBERT, 1975; THEUER \& VITALE, 1977; WELLING, 1977).

3. Formação de sais insolúveis. A absorção do sulfato de zinco, quando ingerido com refeições ricas em cálcio, fosfatos e fitados, diminui consideravelmente, pois, forma com eles sais insolúveis que se precipitam e não são absorvíveis (PÉCOUD et alii, 1975).

4. Aumento da solubilidade. A griseofulvina é um antifungo sistêmico cuja absorção aumenta quando ingerida com dieta hiperlipídica, conforme observaram KABASAKALIAN et alii (1970); esses autores verificaram ainda um fato interessante: quando administrada em jejum, a griseofulvina foi mais bem absorvida à tarde do que de manhã, o que levou os autores a sugerirem a existência de um ritmo circadiano tanto da motilidade intestinal como da secreção biliar, que afetaria a absorção da droga.

5. Inibição competitiva. A interferência desse mecanismo na absorção de drogas tem sido registrada entre a levodopa (L-dopa) usada no tratamento da doença de Parkinson e aminoácidos neutros da dieta. A dieta rica em proteínas tende a cancelar os efeitos terapêuticos e colaterais da droga, ao passo que a dieta pobre em proteínas potencializa e estabiliza o seu efeito (GILLESPIE et alii, 1973). Os aminoácidos competem com a levodopa, não só pela absorção intestinal como também pela penetração no cérebro (WELLING, 1977). Assim, pacientes, em dietas hipoprotéicas, permanecem mais estáveis quando esta é fracionada 
em oito vezes, em lugar de três vezes, provavelmente devido ao menor aumento do nível pós-prandial de aminoácidos, e, conseqüentemente, menor competição pela penetração no cérebro.

\section{INTERAÇÃO FLUIDO - DROGA}

Esse aspecto tem recebido pouca atenção conforme mostra WELLING (1977) em seu trabalho de revisão.

Apesar de ser aceito comumente que uma droga é mais bem absorvida quando em soluções concentradas, os estudos existentes mostram, em geral, o contrário: quando ingeridas com volumes maiores de água, certas drogas são absorvidas mais rapidamente sem alterações da quantidade absorvida (WELLING et alii, 1975); outras mostram somente aumento de quantidade absorvida (BOROWITZ et alii, 1971), enquanto algumas resultam em aumento, tanto da quantidade como da velocidade de absorção (WELLING et alii, 1978).

BOROWITZ et alii (1971) sugerem que a melhor absorção da droga quando em soluções diluídas se deva ao esvaziamento estomacal mais acelerado (como se sabe, ele é retardado em proporção à osmolaridade da solução introduzida no estômago) e também, à exposição da droga a uma superfície absortiva significativamente maior.

Parece, portanto, que, similarmente à interação alimento-droga, a relação existente entre volume de água e droga é bastante complexa, dependendo não só de fatores fisiológicos como também das características físico-químicas da droga.

\section{INCOMPATIBILIDADE DROGA - ALIMENTO}

Os inibidores da MAO (monoamino oxidase), usados no tratamento da depressão, são drogas que inibem as enzimas que degradam a serotonina, epinefrina e outros compostos; como resultado, essas substâncias se acumulam no organismo provocando um estado de euforia.

A tiramina é um composto farmacologicamente ativo que se forma pela descarboxilação bacteriana do aminoácido tirosina, que é normalmente degradada pela via da MEAO. Quando do uso de inibidores dessa via metabólica, a tiramina se acumula, provocando uma severa hipertensão, cefaléia e palpitações (MITCHELL et alii, 1978; DAVIDSON et alii, 1979). Portanto, os alimentos ricos em tiramina como os queijos fortemente curados (de odor forte, tipo Cheddar) devem ser excluidos da dieta de individuos que fazem uso dessa droga. Outros alimentos que contem tiramina ou dopamina (outra amina que exerce o mesmo efeito) são: fígado de galinha, vinho, vinagre de vinho, arenque em conserva, feijão fava, iogurte, cerveja, chocolate, bacalhau em molho de soja (MITCHELL et alii, 1978). 
O dissulfêto de tetra-etiltiuram inibe a aldeído-deidrogenase que catalisa a oxidação do aldeído acético proveniente da metabolização do etanol (OGA, 1979). Assim, quando individuos que utilizam essa droga consomem álcool, o nível de aldeído acético do sangue aumenta consideravelmente, provocando a chamada "síndrome do aldeído acético" que é caracterizada por vasodilatação generalizada, latejamento na cabeça e pescoço, vômito, dificuldade respiratória, sede, dor no peito, fraqueza e vertigem entre outros sintomas.

Essa incompatibilidade tem sido aplicada no tratamento do alcoolismo crônico no sentido de cercear o consumo de álcool, devido ao intenso mal estar que ele provoca nos indivíduos que utilizam a droga. Reações similares podem ocorrer quando indivíduos em tratamento com metronidazol ou sulfoniluréias consomem álcool.

\section{COMENTÁRIOS E CONCLUSŐES}

Do total de 55 drogas e preparações estudadas até 1977, somente 4, não sofreram alteração no nível de absorção quando ingeridas com alimentos; as outras 51 mostraram aumento ou diminuição da velocidade e/ou extensão de absorção (WELLING, 1977).

A mistura de drogas com líquidos ou sua ingestão com alimentos, para mascarar o sabor às vezes desagradável da droga ou por simples casualidade ou desconhecimento, pode criar uma nova série de problemas.

Esses efeitos, entretanto, só serão clinicamente significativos dependendo da intensidade da alteração e do tipo da droga: pode não ser importante no caso de uma droga que dependa de ampla faixa de dosagem para ser efetiva; mas, pode ser importante para sedativos, hipnóticos e outras drogas das quais se deseja uma pronta resposta (McLEAN et alii, 1978) ou para os antibióticos que requerem concentração inibitória mínima, a fim de contra atacar os microorganismos contaminantes (WELLING, 1977).

TOOTHAKER \& WELLING (1980) lembram, também, que drogas cuja uniformidade de dosagem é importante, ou drogas que exibem resposta clínica variada conforme alterações na biodisponibilidade, ou drogas com meia vida biológica curta são as mais afetadas.

É evidente, portanto, a importância de maior conhecimento a respeito da interação existente entre os fatores nutricionais e as drogas, não só para o melhor controle do uso clínico das mesmas como para orientação mais adequada das pessoas que as utilizam.

Por exemplo, algumas drogas são irritantes do trato gastrintestinal; mas, se diluídas quando ingeridas com alimentos, esse efeito é minimizado; assim, a nitrofurantoina, que apresenta esse inconveniente, deve ser ingerida concomitantemente com os alimentos, pois, isso resulta em melhor absorção da droga (BATES et alii, 1974; RESENBERG, \& BATES, 1976). 
O lítio, usado no tratamento de doenças mentais, deve ser administrado após as refeições, pois tem ação purgativa, causando diarréia em alguns indivíduos quando ingerido em jejum (JEPPSON \& SJOGREN, 1975).

Alguns pacientes, quando utilizam a digoxina em jejum, apresentam náusea que parece estar relacionada com o pico máximo de concentração plasmática da droga.

Conforme foi visto, a ingestão da digoxina junto com alimentos afeta apenas a velocidade de sua absorção, sem haver alteração da quantidade total absorvida (GREENBLATT et alii, 1974; JOHNSON et alii, 1978).

Como a ação da digoxina depende mais da sua concentração nos receptores do miocárdio e, como parece que há no mínimo uma demora de 6 horas após a ingestão oral, antes que a concentração plasmática esteja em equilíbrio com a do miocárdio, é provável que esse retardo resultante da ingestão alimentar tenha pouca importância; assim, JOHNSON et alii (1978) sugerem o seu uso logo após as refeições em indivíduos susceptíveis à náusea.

Tendo em vista a importância prática do conhecimento da interação droga-alimento, ROE (1978) aponta a necessidade de:

1) investigações sistemáticas a respeito do efeito de componentes alimentares sobre a biodisponibilidade de drogas;

2) modelos de estudos dietéticos a serem incorporados nos protocolos para o teste de novas drogas em animais e em ensaios clínicos;

3) desenvolvimento de sistemas de identificação de drogas;

4) elaboração de manuais que indiquem as incompatibilidades e a interação droga-alimentos.

Anexamos ao presente trabalho uma lista de drogas estudadas e cuja absorção pode ser afetada quando ingeridas com alimentos ou refeições.

SHIMA, H. Drugs and nutrition: interactions and incompatibilities. Rev. Esc. Enf. USP,

São Paulo, 16(3):255-264, 1982.

The use of drugs with foods or fluids can alter their absorption level. Moreover, some constituents of certain foods cannot be ingested with some drugs because they cause adverse effects. This paper presents these interactions and incompatibilities between drugs and food. 


\section{REFERÊNCIAS BIBLIOGRÁFICAS}

BATES, T. R. et alii. Effect of food on nitrofuratoin absorption. Clin. pharmacol, Ther., Washington, 16(1):63-8, 1974.

BORCWITZ, J. L. et alii. Mechanism of enhanced drug effects produced by dilution of the oral dose. Toxicol. appl. Pharmacol. New York, 19:164-8, 1971.

DAVIDSON, S. et alif. Human nutrition and dietetics. Edimburg, Churchill Livingstone, 1979. p. 196.

GIESBRECHT, A. M. \& ZYNGIER, S. B. Absorção e distribuịcão de drogas. In: ZANINI, A. C. \& OGA, S. Farmacologia aplicada. Săo Paulo, Atheneu, 1979. cap. 3, p. 27-33.

GILLESPIE, N. G. et alii. Diets affecting treatment of parkinsonism with levodopa. J. Amer. diet. Ass., Chicago, 62:525-8, 1973.

GREENBLATT, D. J. et alii. Bioavailability of digoxin tablets and elixir in the fasting and postprandial states. Clin. pharmacol. Ther. St. Louis, 16(1):444-8, 1974.

Louis, 24:600-9, 1978 .

HATHCOCK, J. N. Nutrition: toxicology and pharmacology. Nutr. Rev., New York, 34 (3) :65-70, 1976.

JEPPSON, J. \& SJOGREN, J. The influence of food on side effects and absorption of lithium. Acta psychiat. scand., Kebenhavn, 51:285-8, 1975.

JOHNSON, B. F. et alii. Effect of a standart breakfast on digoxin absorption in normal subjects. Clin. pharmacol. Ther., St. Louis, 23:315-9, 1978.

JUSKO, W. J. \& LEVY, G. Absorption, metabolism and excretion of riboflavin-5' phosphate in man. J. pharm. Sci., Washington, 56:58-62, 1967.

KABASAKALIAN, P. et alii. Parameters affecting absorption of griseofulvin in a human subject using urinary metabolite excretion data. J. pharm. Sci., Washington, 59:595-600, 1970.

KOCH-WESER, J. Biovailability of drugs. New Engl. J. Med., Boston,291(5)233-7, 1974.

LAMBERT Jr, M. L. Drugs and diet interactions. Am. J. Nurs. New York, 75(3):402-6, 1975.

LEVY, G. \& JUSKO, W. J. Factors affecting the absorption of riboflavin in man. J. pharm. Sci., Washington, $55: 285-9$, 1966 .

McLEAN, A. J. et alii. Food, splanchnis blood flow and biovailability of drugs subject to first-pass metabolism. Clin. pharmacol. Ther., St. Louis, 24:5-10, 1978.

MELANDER, A. et alii. Enhancement by food of canrenone biovailability from spironolactone. Clin. pharmacol. Ther., St. Louis, 22(1):100-3, 1977.

MITCHeLL, H. S. et alii. Nutrição. Rio de Janeiro, Interamericana, 1978. cap. 33, p. $463-6$.

OGA, S. Biotransformação e excreção de drogas. Iñ: ZANINI, A. C. \& OGA, S. Farmacologia aplicada. Såo Paulo, Atheneu, 1979. cap. 5. p. 42-52.

PeCOUD, A. et alii. Effect of foodstuffs on the absorption of zinc sulphate. Clin. pharmacol. Ther., St. Louts, 17:469-74, 1975.

RESENBERG, H. A. \& BATES, T. R. The influence of feod on nitrofurantoin bioavailability. Clin. pharmacol. Ther., St. Louis, 20:227-32, 1976.

ROE, D. A. Diet-drug interactions and incompatibilities. In: HATHCOCK, J. N. \& COON, J. Nutrition and drue interrelations. New York, Academic Press, 1978. cap. 11, p. 319-45.

SENNELLO, L. T. et alii. Effect of food on kinetics of the nonsteroidal anti-inflamative alclofenac. Clin. pharmacol. Ther., St. Louis, 23:414-20, 1978.

THEUER, R. C. \& VITALE, J. J. Drug and nutrient interactions. In: SCHNEIDER, H. A. et alif. Nutritional support of medical practice. New York, Harper \& Row, 1977. cap. 18, p. $297-305$.

TOOTHAKER, R. D. \& WELLING, P. G. The effect of food on drug biovailability. Ann. Rev. Pharmacol. Toxicol., Palo Alto, 20:173-99, 1980.

WELLING, P. G. et alii. Influence of diet and fluid on bioavailability of theophylline. Clin. pharmacol. Ther., St. Louis, 17:475-80, 1975.

WELLING, P. G. Influence of food and diet on gastrointestinal drug absorption: a review. J. Pharmacokin. Biopharm., San Francisco, 5(4):291-334, 1977.

WELLING, P. G. et alli. Bioavailability of erythromicin stearate: influence of food and fluid volume. J. pharm. Sci., Washington, 67(6):764-6, 1978. 


\section{A NEXO}

\section{I - INTERACGAO DROGA-NUTRIÇAO}

1. Drogas cuja absorção pode ser aumentada quando:

— ingeridas com leite - etilsuccinato de eritromicina

- ingeridas com refeições lipídicas - griseofulvina (GRISOVIN, FULCIN, GRIFULVIN) *

-- ingeridas com outros alimentos - nitrofurantoína (FURADANTINA,

- propoxifeno MACRODANTINA)

- riboflavina

- riboflavina-5'-fosfato

- espironolactona (ALDACTONE)

- propanolol (INDERAL)

- metoprolol

- diazepan (VALIUM)

- cefalexina (KEFLEX, CEPOREXIN)

- citrato de lítio**

2. Drogas cuja absorção pođe ser reduzida quando:

— ingeridas com leite - metaciclina

- cefalexina (KEFLEX, CEPOREXIN)

- tetraciclina (TETREX, TERRAMICINA, TETRIN)

- desmetil-cloro-tetraciclina (LEDERMICINA)

- pivampicilina (ALPHACILINA)

- sulfato de zinco

- ingeridas com alimentos protéicos - levodopa (LARODOPA, APARIZAZIN, SINEMET, MADOPAN)

- ingeridas com refeição rica em lipides - rifampicina (RIFALDIN, RIMACTAN)

- ingeridas com outros alimentos — penicilina G (PENTID)

- fenilmercapto - metil - penicilina

- penicilina $\mathrm{V}(\mathrm{K})$ (PEN-VE-ORAL)

- penicilina $\mathrm{V}(\mathrm{Ca})$

- penicilina $\mathrm{V}$ (ácida)

- feneticilina

- ampicilina (BINOTAL, PENBRITIN, AMPICIL, POLICILLIN)

- amoxilina (AMOXIL, AMOXIDAL, AMOXIPEN)

- pivampicilina (ALPHACILINA)

- tetraciclina (TETREX, TERRAMICINA, TETRIN)

- desmetil - cloro - tetraciclina (LEDERMI-

- propantelina (PRO-BANTHINE)

- ácido acetil salicílico

\footnotetext{
* termos entre parêntesis corresponde a nome comercial da droga.

* não deve ser administrado a pacientes com dieta isenta de Na pois a excreça renal do litio e retardada, podendo ocasionar intoxicação.
} 
3. Drogas cuja absorção pode ser retardada quando ingeridas com alimentos:

— amoxilina (AMOXIL, AMOXIDAL, AMOXIPEN)

- cefalexina (KEFLEX, CEPOREXIN)

- cefradina (CEFRADAL)

- sulfanilamida

- sulfadiazina (SULFADIAZINA)

- sulfadimetoxina (MADRIBON)

- sulfa-metoxi-piridazina (LEDERKYN, LONGUN)

- sulfissoxazol (GANTRISIN)

- sulfasimazina

- ácido acetil salicílico

- acetaminofena (ACETOFEN, ALIVIOL, ERALDOR)

- digoxina (LANOXIN)

- furosemida (LASIX)

- ion potássio

- diazepan (VALTUM)

- alclofenaque (ZUMARIL)

- fenobarbital (GARDENAL, FENOBARBITAL)

- amobarbital

\section{II - INCOMPATIBILIDADE DROGA-ALIMENTO}

\begin{tabular}{|c|c|c|c|}
\hline $\begin{array}{l}\text { Droga ou } \\
\text { Grupo de Drogas }\end{array}$ & Alimentos & $\begin{array}{c}\text { Componente } \\
\text { Tóxico }\end{array}$ & Efeitos Agudos \\
\hline $\begin{array}{l}\text { Inibidores da MAO } \\
\text { (PARNATE) }\end{array}$ & $\begin{array}{l}\text { queijos curados, vi- } \\
\text { nho, levedo, arenque } \\
\text { em conserva, feijão } \\
\text { fava, figado de gali- } \\
\text { nha, vinagre de vinho }\end{array}$ & $\begin{array}{l}\text { tiramina } \\
\text { e/ou } \\
\text { dopamina }\end{array}$ & $\begin{array}{l}\text { crises hipertensi- } \\
\text { vas }\end{array}$ \\
\hline $\begin{array}{l}\text { Sulfoniluréias (DIA- } \\
\text { BINESE, RASTI- } \\
\text { NON, ORINASE) }\end{array}$ & bebidas alcoólicas & etanol & $\begin{array}{l}\text { ataque hipoglicê- } \\
\text { mico }\end{array}$ \\
\hline $\begin{array}{l}\text { Bissulfeto de tetra- } \\
\text { etil tiuram (ANTA- } \\
\text { BUSE, ANTIETA- } \\
\text { NOL) e } \\
\text { Metronidazol (FLA- } \\
\text { GYL) }\end{array}$ & bebidas alcoólicas & etanol & $\begin{array}{l}\text { "síndrome do } \\
\text { aldeído-acético" }\end{array}$ \\
\hline
\end{tabular}

